\title{
Desenvolvimento científico e desafios da Psicologia do Trabalho e das Organizações no Brasil
}

\section{Scientific development and challenges of Work and Organizational Psychology in Brazil}

\section{Desarrollo Científico y desafíos de la Psicología del Trabajo y de las Organizaciones en Brasil}

\author{
Sonia Maria Guedes Gondim* \\ Universidade Federal da Bahia - UFBA, Salvador, Bahia, Brasil \\ J airo Eduardo Borges-Andrade** \\ Universidade de Brasília - UnB, Brasília, Distrito Federal, Brasil
}

\section{Antônio Virgílio Bittencourt Bastos***}

Universidade Federal da Bahia - UFBA, Salvador, Bahia, Brasil

\begin{abstract}
RESUMO
Discorre-se sobre o desenvolvimento brasileiro da psicologia do trabalho e das organizações, com o foco na sua formação pós-graduada e produção científica. Inicia-se pela demarcação conceitual. Na seção subsequente, argumenta-se a favor da relação entre o crescimento e a diversificação da subárea e também a expansão da pós-graduação no Brasil. Segue um panorama das revisões de literatura nacionais, visando ressaltar a diversidade na prática de pesquisa. Finaliza-se com considerações sobre os desafios para alcançar níveis mais elevados de amadurecimento científico.

Palavras chave: métodos de pesquisa, psicologia organizacional, psicologia do trabalho, pós-graduação.
\end{abstract}

\begin{abstract}
This article aims to describe the Brazilian development of work and organizational psychology, with a focus on its graduate training and scientific production. It begins by defining concepts. The following section argues in favor of the relationship between growth and diversification of the subarea and the expansion of graduate programs in Brazil. An overview of the national scientific reviews follows, in order to mark the diversity in research practices. Finally, the chapter discusses challenges to achieve higher levels of scientific maturity.

Keywords: research methods, work psychology, organizational psychology, graduate studies.

\section{RESUMEN}

Se aborda el desarrollo brasileño de la psicología del trabajo y de las organizaciones, con el foco en su formación en el posgrado y producción
\end{abstract}


científica. Se inicia por la demarcación conceptual. En la sección posterior, se argumenta a favor de la relación entre el crecimiento y la diversificación del sub-área y también la expansión del posgrado en el Brasil. Se propone un panorama de las revisiones de literatura nacionales, con vistas a resaltar la diversidad en la práctica de investigación. Se concluye con consideraciones sobre los desafíos para alcanzar niveles más elevados de madurez científica.

Palabras clave: métodos de investigación, psicología organizacional, psicología del trabajo, posgrado.

Mapear a amplitude e complexidade da subárea da psicologia do trabalho e das organizações, ou psicologia organizacional e do trabalho (PO\&T), é uma tarefa sempre inconclusa e não é pela escassez de produção teórica ou empírica (e.g., Bendassolli \& BorgesAndrade, 2015; Borges \& Mourão, 2013; Puente-Palácios \& Peixoto, 2015; Zanelli, Bastos \& Borges-Andrade, 2004, 2014). Razões que impõem desafios àquele mapeamento são: a) a multi e interdisciplinaridade da subárea; b) a constante tensão entre as demandas científicas de compreensão e intervenção e as questões práticas de organizações, gestores, trabalhadores e formuladores de políticas públicas laborais; e c) os múltiplos níveis em que se estruturam essas questões e as esferas globais e locais nem sempre convergentes. Da psicologia, essa subárea herda tensões, como por exemplo, a de caracterizar-se como ciência e profissão. Outra herança vem das ciências humanas e sociais, em que diversos paradigmas estão em permanente conflito. $O$ frequente descompasso entre o nível teórico de constructos e sua mensuração promove outra complexidade, pois não há definições operacionais amplamente compartilhadas na comunidade científica. Isso repercute na variedade de temas investigados. Essa subárea, portanto, afirma-se como multifacetada, plural e em certo sentido contraditória. Nela atuam aproximadamente $1 / 4$ dos profissionais de psicologia (Bastos \& Gondim, 2010). Mas sua comunidade científica ainda possui proporções reduzidas. Há distância entre o volume de questões da prática profissional e a produção de conhecimento científico. Falta uma ampla rede dedicada à formação nos níveis de mestrado e doutorado (Borges-Andrade \& Zanelli, 2014). Em consequência, proliferam práticas sem respaldo científico e modismos importados que prometem soluções mágicas para problemas complexos.

A psicologia organizacional tem interesse no estudo das organizações como processos sociais estruturantes. Relações entre comportamento humano e organização são seu principal objeto de estudo, nos níveis macro (estrutura), meso (grupos) e micro (indivíduo) do comportamento organizacional. O trabalho entra como a dimensão que une os três níveis. A psicologia do trabalho tem seu principal foco no fenômeno do trabalho, em qualquer contexto onde ele estiver sendo desenvolvido e não somente nas organizações. A gestão de 
pessoas, a seu turno, tem como foco a utilização do conhecimento produzido em comportamento organizacional e em psicologia do trabalho. Essa utilização é feita por profissionais de distintas áreas do conhecimento, inclusive da psicologia. Ocupar-se-iam dos processos de ingresso e desenvolvimento nas organizações (recrutamento e seleção, socialização, treinamento), fixação (planos de cargos, salários e de carreira), acompanhamento e avaliação do desempenho e impactos de mudanças organizacionais. Existe no contexto brasileiro grande diversidade, ampliação de subdomínios temáticos e aproximações com campos científicos afins. Esse quadro decorre, principalmente, da PO\&T se apresentar também como campo de aplicação, o que faz com que seja continuamente pressionado por inúmeras demandas sociais, organizacionais e de campos disciplinares afins, que forçam a incorporação de outros tópicos de pesquisa e novos rearranjos temáticos direcionando o estudo e a atuação profissional. Apesar de ainda ser de uso corrente a classificação da PO\&T em três subdomínios, organização, trabalho e gestão, estes cresceram e se diversificaram. Contribuíram para isto principalmente as demandas de solução de problemas práticos no contexto da atuação profissional, a aproximação com outros campos científicos como a administração, e também as crises econômicas, sociais e mudanças tecnológicas na sociedade e no mundo do trabalho. Associado a essas razões, o crescimento da pós-graduação no Brasil teve um papel significativo no desenvolvimento e na independência desses subdomínios.

\section{A pós-graduação e a produção do conhecimento}

A expansão do sistema de pós-graduação no Brasil, tanto quantitativa como qualitativamente, é um dos resultados mais positivos de uma política de estado implementada de forma sistemática, há muitas décadas. O aumento dos cursos de pós-graduação stricto sensu em Psicologia no Brasil é algo bem expressivo, se comparados os anos de 1980 e 2016 (Coordenação de Aperfeiçoamento de Pessoal de Nível Superior [CAPES], 2017). Os Mestrados Científicos cresceram de 12 para 79 e os Doutorados de dois para 53. Este crescimento foi acompanhado por uma ampliação das diferentes subáreas que integram o campo da Psicologia, entre elas a PO\&T. Surgiram recentemente os Mestrados Profissionais, inexistentes até 2012, voltados para qualificação em alto nível de profissionais para atuarem em contextos específicos de trabalho. Saltaram de dois para sete em 2016. Há uma enorme demanda de qualificação profissional no campo da psicologia no Brasil que está longe de ser atendida por cursos stricto sensu. Os diversificados perfis de competências profissionais exigidos pelo mercado de trabalho demandam estruturas 
curriculares e modalidades de trabalhos de conclusão de curso distintas das que vigoram nesses cursos. Até a década de 1990, não se contava no Brasil com um curso de pós-graduação stricto sensu em Psicologia totalmente dedicado ao campo da PO\&T. Existiam somente linhas de pesquisa e algumas poucas áreas de concentração. Os interessados migravam para uma pós-graduação lato sensu em gestão de pessoas ou trilhavam o caminho da pós-graduação stricto sensu em programas de psicologia social, ciências sociais, administração, educação e áreas afins. Esse panorama parece ter se alterado com o aumento da pós-graduação em Psicologia ao longo dos últimos 15 anos, especialmente com o aparecimento de outras linhas de pesquisa voltadas para fenômenos na área de PO\&T.

Existem 253 linhas de pesquisa nos atuais 84 Programas de Pósgraduação em Psicologia (CAPES, 2017). São presumidamente sustentadas por grupos de pesquisa estruturados e com um nível de maturidade teórico-metodológica que permite a formação de novos pesquisadores. São 18 as linhas cujo título as vinculam à PO\&T (7,1\% daquele total), ocupando a décima posição entre as diversas subáreas da Psicologia contempladas com as linhas de pesquisa. Portanto, PO\&T é uma subárea de tamanho mediano, não se caracterizando mais como uma clara lacuna no sistema, como o era no início dos anos 2000. Atualmente há um único Programa, na Universidade de Brasília, que oferece cursos de mestrado científico e doutorado em PO\&T, e cobre, também, a área de psicologia social. Em 2015 foi implantado o primeiro mestrado profissional em PO\&T, na Universidade Potiguar, em Natal, Rio Grande do Norte. Nos demais Programas brasileiros, os focos no trabalho ou nas organizações aparecem nas linhas de pesquisa. Um dado importante refere-se à distribuição regional dos programas que possuem essas linhas de pesquisa em PO\&T. Há opções de universidades para esta formação pós-graduada nas diversas regiões do país: cinco no Sudeste, quatro no Nordeste, três no Sul e duas no Centro-Oeste (CAPES, 2017). Não existem na região Norte.

Em outras instituições de ensino superior (IES), encontram-se pesquisadores e projetos vinculados a PO\&T, inseridos em linhas de pesquisa mais amplas. Estão provavelmente em número insuficiente para a composição de uma linha de pesquisa especificamente em PO\&T. Ao se levar em conta os 160 projetos de pesquisa com temas afins a PO\&T, o espaço ocupado nos Programas de Pós-graduação em Psicologia é maior: 15 em IESs (Instituições de Ensino Superior) do Sudeste ( 55 projetos), nove no Nordeste (66 projetos), cinco no Sul (19 projetos) e três no Centro-Oeste (20 projetos) (CAPES, 2017). Constata-se, então que sobe para 36 ( $42 \%$ do total) o número desses Programas que se dedicam a tópicos na área de PO\&T.

Com o intuito de aprofundar a compreensão dos temas, os títulos desses projetos foram analisados pelo Alceste, versão 2010. Trata-se 
de um software de análise quantitativa textual, introduzido no Brasil para o estudo das representações sociais e avaliação de programas sociais e de intervenção (Camargo, 2005). Os títulos dos projetos foram introduzidos como unidades de contexto inicial (U.C.I). O software faz as classificações hierárquicas ascendentes e descendentes constituindo agrupamentos (classes) com base em cálculos da frequência de associação entre as palavras (U.C.E unidades de contexto elementar - unidades básicas de sentido). Oferece três principais outputs: (i) o número de classes e sua representatividade no corpus em análise com base nas U.C.Es.; (ii) relação hierarquizada das U.C.Es. significativas em cada uma das classes com radicais e palavras derivadas; e (iii) disposição espacial de proximidade e distanciamento entre as classes (análise fatorial por correspondência). A Tabela 1 apresenta o resultado de análises do ALCESTE. Foram encontradas oito classes estáveis no corpus (títulos dos projetos de PO\&T), revelando mais uma vez a complexidade que cerca o arranjo dos temas de estudo deste campo no Brasil, ultrapassando a classificação tradicional "trabalho, organização e gestão".

Tabela 1

Classes com sua representatividade no corpus e U.C.Es principais

\begin{tabular}{|c|c|c|c|}
\hline Classe 4 & Classe 2 & Classe 5 & Classe 3 \\
\hline $\begin{array}{c}22 \% \\
\text { U.CEs } \\
\text { Significativas }\end{array}$ & $\begin{array}{c}14 \% \\
\text { U.CEs } \\
\text { Significativas } \\
\end{array}$ & $\begin{array}{c}14 \% \\
\text { U.C.Es } \\
\text { signific ativas }\end{array}$ & $\begin{array}{c}12 \% \\
\text { U.C.Es } \\
\text { Significativas } \\
\end{array}$ \\
\hline $\begin{array}{c}\text { Condiçōes } \\
\text { Precarizaçâo } \\
\text { Saúde } \\
\text { Trabatho } \\
\text { Subjetividads(s) } \\
\text { Rede } \\
\text { Tempo } \\
\text { Mindo } \\
\text { Docente } \\
\text { Fatores } \\
\text { Mercado } \\
\text { Construçảo }\end{array}$ & $\begin{array}{c}\text { Sociat(is) } \\
\text { Clinica(s) } \\
\text { Processo } \\
\text { Carreira } \\
\text { Aposentadoria } \\
\text { Saúde } \\
\text { Trabatho } \\
\text { Mercado }\end{array}$ & $\begin{array}{c}\text { Individuo(ual) } \\
\text { Desempenho } \\
\text { Atuação } \\
\text { Perspectiva } \\
\text { Organizacional(ais) } \\
\text { Ersino } \\
\text { Análise } \\
\text { Escolha } \\
\text { Comprometimento } \\
\text { Psicossociais }\end{array}$ & $\begin{array}{l}\text { Trabathador(es) } \\
\text { Organiz aç ão(ōes) }\end{array}$ \\
\hline Classe 1 & Classe 7 & Classe 8 & Classe 6 \\
\hline $\begin{array}{c}10 \% \\
\text { U.CEs } \\
\text { Significativas }\end{array}$ & $\begin{array}{c}10 \% \\
\text { U.CEs } \\
\text { Significativas }\end{array}$ & $\begin{array}{c}10 \% \\
\text { U.C.Es } \\
\text { Significativas }\end{array}$ & $\begin{array}{c}8 \% \\
\text { U.C.Es } \\
\text { Significativas }\end{array}$ \\
\hline $\begin{array}{c}\text { Desenvolvimento } \\
\text { Intervençöes } \\
\text { Profissional } \\
\text { Cameira } \\
\text { Edvcaçāo } \\
\text { Escotha }\end{array}$ & $\begin{array}{l}\text { Avaliaçảo } \\
\text { Instrumento } \\
\text { Treinamento } \\
\text { Contexto } \\
\text { Impacto } \\
\text { Construçảo } \\
\text { Desempenho }\end{array}$ & $\begin{array}{c}\text { Geståo } \\
\text { Contexto(s) } \\
\text { Cultura(1) } \\
\text { Organizacional(is) } \\
\text { Bem-estar } \\
\text { Impacto(s) } \\
\text { Professores } \\
\text { Universitários }\end{array}$ & $\begin{array}{c}\text { Relação( ôes) } \\
\text { Atividads(s) } \\
\text { Trabalho } \\
\text { Vida } \\
\text { Tempo } \\
\text { Práticas } \\
\text { Orientaçảo } \\
\text { Contemporâneas }\end{array}$ \\
\hline
\end{tabular}

Nota. A ordem de apresentação das U.C.Es está hierarquizada conforme o valor do qui-quadrado em cada classe. Preposições e palavras de ligação foram retiradas da hierarquia. $82 \%$ do corpus foi analisado e organizado em U.C.Es significativas.

Fonte: Elaborado pelos autores com base nos outputs do Alceste. 
Na Tabela 1 observa-se que a Classe 4 é a mais representativa dos títulos dos projetos, respondendo por $22 \%$ das U.C.Es. Os pesquisadores desta área estudam questões relativas à precarização do trabalho, à saúde e à subjetividade do trabalhador. As Classes 2 e 5 respondem cada uma por $14 \%$ das U.C.Es. A primeira sugere ter um foco mais clínico e social com relações com a saúde, a aposentadoria e a carreira enquanto a segunda sugere foco maior em questões psicossociais e de análises organizacionais, envolvendo escolhas, desempenho e padrões de comprometimento. A Classe 3 parece mais focada nas relações entre trabalhadores e organizações, mas não oferece informações adicionais para saber como estas relações são tratadas. As Classes 1,7 e 8 respondem por $10 \%$ das U.C.Es cada uma. O foco da Classe 1 está no desenvolvimento e intervenções no âmbito de carreiras, educação e escolhas profissionais. A Classe 7 representa mais claramente a área da gestão, com foco na construção de instrumentos, avaliação de desempenho e análise de impactos do treinamento. A Classe 8 também se dedica a questões da gestão, mas parece focar mais no contexto cultural e organizacional e suas relações com o bem-estar. De certo modo, parece dar subsídios indiretos para a gestão. A Classe 6 , que representa somente $8 \%$ das U.C.Es, sugere estar dedicada a questões contemporâneas que articulam atividades, trabalho, vida, tempo, práticas e orientações. No entanto, não fica claro como se dão as relações entre esses tópicos. A situação de indefinição, no entanto, é menos pior do que ocorre na Classe 3 , onde somente duas palavras compuseram as U.C.Es.

Outro elemento importante da análise se refere a como as Classes se posicionam em termos de proximidade e distanciamento entre si. A Figura 1 ilustra esta disposição espacial. As Classes 4,3 e 2 encontram-se mais próximas, sendo que a Classe 4 , a mais representativa da área de PO\&T, posiciona-se mais distante do eixo, marcando oposição com as Classes 7 e 8 que se situam no quadrante oposto. Em outras palavras, quem se dedica ao estudo das condições de precarização do trabalho se situa distante de quem está mais dedicado a questões conceituais e instrumentais da gestão organizacional (treinamento, cultura, bem-estar, desempenho). As Classes 5 e 1 se encontram mais próximas, o que sugere que há diálogo entre questões teórico-conceituais que marcam o estudo de processos micro-organizacionais e dos vínculos do trabalhador com a organização e os estudos de intervenção no âmbito da carreira e escolha profissional, ou seja, vínculos com a carreira. A Classe 6 encontra-se próxima da Classe 2, mas parece ainda não revelar uma identidade clara de pertencimento.

A análise foi feita com base em títulos de projetos e não nos resumos, que certamente oferecem informações mais precisas das 
relações entre os construtos estudados. O esforço, todavia, serve de ensaio analítico de tendências temáticas e do jogo de forças na subárea de PO\&T. Elas precisarão ser interpretadas à luz de outros estudos. Considerando esses projetos na pós-graduação, há que verificar as características da pesquisa nessa subárea, divulgada por meio de publicações no Brasil.

Classe 8

Classe 7

Classe 6

Classe 2

Classe 5

Classe 3

Classe 4

Classe 1

Figura 1. Disposição das oito Classes em quadrantes. O tamanho da fonte visa destacar a representatividade da Classe.

Fonte: Elaborado pelos autores com base nos outputs do Alceste.

\section{As características da pesquisa publicada}

Existem muitas revisões sobre a produção do conhecimento em PO\&T. No Brasil, no século XXI, cresceu este tipo de publicação, muito provavelmente em decorrência da expansão dos relatos de pesquisas sob a forma de artigos nesta subárea, resultantes provavelmente de projetos como aqueles mencionados e analisados na seção anterior.

Esta seção está dividida em duas partes. Na primeira são mencionadas as revisões mais gerais da subárea e, na segunda, algumas revisões de temas específicos, alguns deles nacionalmente consolidados, outros ainda carentes de investigação no Brasil. Nessas revisões predominaram análises de artigos publicados no presente século, em periódicos de psicologia e de administração, pois em ambos os casos há relatos de pesquisa sobre PO\&T. 
Uma análise de 194 publicações sobre estudos organizacionais, no período de 2000 e 2001, em três periódicos estrangeiros (Organizational Studies, Administrative Science Quartely e Academy of Management Journal) e três nacionais (Revista de Administração de Empresas, Revista de Administração da USP e Revista de Administração Pública) foi realizada por Vergara e Peci (2003). O foco recaiu sobre objetivos, instrumentos de coleta de dados, corte temporal e análise de dados. Estudos com foco na explicação ( $55 \%$ teste de hipóteses, relações de causa e efeito) predominam sobre a exploração (19\%) e a descrição (7,3\%). Mas isto aparece de modo mais visível nos periódicos estrangeiros. Nos nacionais predominam estudos qualitativos descritivos e interpretativos. O uso combinado de técnicas de coleta de dados predomina, como por exemplo, questionários e entrevista, visando triangulação (várias fontes de coleta de dados, buscando a convergência e a complementaridade). $\mathrm{O}$ corte transversal $(55,32 \%)$ prevalece sobre as pesquisas longitudinais $(43,26 \%)$. O tratamento quantitativo (51\%) prevalece sobre o qualitativo $(37,58 \%)$, e o restante combina as duas modalidades. Esta revisão cobriu investigações realizadas no nível macro, o que geralmente não é feito por pesquisadores da psicologia, que concentram seus esforços nos níveis micro e, em menor quantidade, no nível meso de análise.

Estudo sobre o desenvolvimento científico da PO\&T cobriu o período de 2001 a 2005 e analisou artigos de sete periódicos vinculados à área da psicologia (Tonetto, Amazarray, Koller, \& Gomes, 2008). Os resultados apontam que os desenhos de pesquisa quantitativa $(46,8 \%)$ predominaram sobre os de natureza qualitativa $(37,3 \%)$, sendo que apenas $16,6 \%$ foram mistos. Os resultados encontrados por estes autores sinalizaram poucos trabalhos sobre recrutamento e seleção, mas um crescente aumento de estudos sobre treinamento. Os temas mais investigados estavam relacionados à saúde e ao trabalho. Haveria também considerável ênfase nas relações entre modelos de gestão, formas de subjetivação e saúde mental. A mesma revisão indicou, em relação às referências utilizadas, a menção tanto à literatura nacional quanto estrangeira. Mas enquanto as referências estrangeiras são de artigos publicados em periódicos, a nacional se apoiava principalmente em livros.

Outra revisão nacional cobriu relatos de pesquisa empírica sobre micro comportamento organizacional publicados entre 1996 e 2009, em 14 periódicos de administração (60\%) e psicologia (40\%) (Borges-Andrade \& Pagotto, 2010). Portanto, em relação às duas revisões anteriores, tentou-se aumentar o número de periódicos e incluir essas duas áreas de conhecimento. Foram encontrados mais artigos em periódicos de administração, exceto no caso da Revista Psicologia: Organizações e Trabalho (rPOT). Estes autores mostraram uma quantidade anual entre 10 e 20 artigos, até o ano 2000, seguida 
por uma quantidade entre 30 e 40, a partir do ano seguinte. Teria ocorrido um crescimento substancial, na virada do século. Não por coincidência, isto ocorreu no período da expansão da pós-graduação em PO\&T, relatada na seção anterior.

As categorias de variáveis critério mais estudadas nesses artigos foram, em ordem decrescente (em uma lista de 17 categorias): (i) afeto no trabalho, (ii) aprendizagem formal e informal no trabalho, (iii) interações sociais nas equipes e nas organizações, (iv) bem-estar e saúde no trabalho, (v) identidade e significados do trabalho e seus produtos e (vi) cognição no trabalho. No outro extremo, as menos estudadas foram (também em ordem decrescente de número de artigos): (i) clima organizacional, (ii) desvios de comportamento no trabalho, (iii) tomada de decisão e julgamentos no trabalho, (iv) motivação no trabalho, (v) fuga e esquiva no trabalho e (vi) criatividade e solução de problemas nas organizações (BorgesAndrade \& Pagotto, 2010).

A análise dos artigos revisados permitiu inferir que seus objetivos estavam mais direcionados para a geração de conhecimentos e, em sequência, para o desenvolvimento de instrumentos de medida. Teria ocorrido amadurecimento dos desenhos de investigação, provavelmente em decorrência do fortalecimento de linhas de pesquisa em programas de pós-graduação, argumentam BorgesAndrade e Pagotto (2010). Esses desenhos adotaram abordagens metodológicas quantitativas ou qualitativas, em números equivalentes, seguidos por abordagens que as combinam (em números bem mais modestos). Os beneficiários foram igualmente os setores público e privado da economia e o terceiro setor foi pouco estudado. O segmento terciário da economia (serviços) foi o mais investigado, seguido de muito longe pelo setor secundário (industrial), confirmando que tal adjetivo não mais qualifica adequadamente a PO\&T e suas pesquisas. O segmento primário teve números bastante inexpressivos. Este segmento nunca foi contexto privilegiado de pesquisas em PO\&T.

Além das pesquisas sobrea temática microcomportamento nas organizações de trabalho, os estudos sobre gestão de pessoas também foram abordados por Borges-Andrade e Pagotto (2010). Concluíram que estas não conseguiram alcançar os padrões das pesquisas sobre aquela temática, exceto no caso de treinamento, desenvolvimento e educação nas organizações (TD\&E). Portanto, haveria muito o que fazer, no caso de recrutamento e seleção e avaliação de desempenho, por exemplo. Propuseram uma agenda estratégica para a pesquisa nacional em PO\&T, envolvendo a construção de medidas e os testes de modelos de predição, prioritariamente para temas como clima organizacional, desvios de comportamento, tomada de decisões, motivação, fuga e esquiva, criatividade e solução de problemas, seleção e avaliação de 
desempenho. Argumentaram que o foco nestes temas deveria seguir os bons exemplos teórico-metodológicos existentes, em temas como valores, contratos psicológicos, aprendizagem, percepção de justiça e equidade e TD\&E. Sugeriram ainda a criação de redes de investigadores para aqueles temas, nos moldes dos temas mais estruturados. Discutiram a necessidade de diversificar métodos de pesquisa, temáticas da psicologia e setores e segmentos da economia e intensificar estudos de nível meso e macro. Finalizaram discutindo estratégias mais apropriadas de divulgação dessa produção.

Outra análise de produção científica foi feita a partir do levantamento de artigos publicados em 15 periódicos de administração e psicologia indexados no Scielo: portanto, uma base de dados parcialmente distinta (sete periódicos comuns) daquela utilizada pelos dois autores anteriormente mencionados (Andrade \& Frossard, 2013). Seu foco foi nos fatores humanos no trabalho, que contemplariam tanto as práticas de gestão e os processos organizacionais, quanto 0 entendimento dos determinantes do processo de saúde no trabalho. Embora este foco esteja muito próximo daquele descrito por BorgesAndrade e Pagotto (2010), o período temporal foi menor: 2005 a 2010. Tal como na revisão anteriormente citada, Andrade e Frossard (2013) encontraram maior número de artigos em periódicos vinculados à área da administração e constataram ainda uma expansão no número anual de publicações, também associada ao aumento das oportunidades na pós-graduação.

Os conteúdos dos artigos foram analisados por Andrade e Frossard (2013), enquanto Borges-Andrade e Pagotto (2010) analisaram variáveis critério. Como estes, Andrade e Frossard (2013) analisaram métodos de investigação dos artigos e elaboraram 14 categorias para classificá-los. Estas categorias, no entanto, não se mostraram tão discrepantes numericamente quanto as encontradas por BorgesAndrade e Pagotto (2010). A categoria mais frequente encontrada por Andrade e Frossard (2013) foi saúde mental no trabalho. Em seguida, com frequências bem próximas, apareceu uma grande e diversificada quantidade de assuntos, cujos números nunca alcançaram sequer a metade da quantidade dos artigos sobre saúde mental no trabalho. Os números mais baixos foram os referentes a práticas relativas à gestão de pessoas, como recrutamento e seleção e avaliação de desempenho, e aspectos meso-organizacionais, tal como foi apontado por Borges-Andrade e Pagotto (2010).

O delineamento metodológico prevalente, identificado por Andrade e Frossard (2013), foi o do tipo survey, seguido de perto por pesquisa documental, depois entrevistas e estudos de caso. Outros tipos de delineamentos foram muito pouco frequentes, assim como a combinação de técnicas de investigação. Este quadro provavelmente apoiaria a agenda estratégica de caráter metodológico proposta por Borges-Andrade e Pagotto (2010). Não é possível afirmar algo similar 
a respeito da agenda estratégica que estes autores propuseram para as distintas categorias de variáveis critério que utilizaram, pois estas não são comparáveis com as categorias formuladas por Andrade e Frossard (2013).

Uma terceira revisão geral cobriu o período entre 2001 e 2010, mas focou exclusivamente em gestão de recursos humanos (Meneses, Coelho Jr., Ferreira, Paschoal, \& Silva Filho, 2014). Analisaram-se artigos publicados somente em periódicos da administração, ciências contábeis e turismo, classificados entre A1 e B4 no Qualis/CAPES. Apesar desta restrição, um quarto dos autores tinha formação em psicologia, seguida da formação em administração. Tal achado confirmou o que já tinha sido encontrado pelos autores das duas revisões anteriormente citadas aqui: é frequente a presença de pesquisadores com formação em psicologia que publicam em periódicos de administração.

As duas temáticas mais frequentes dos artigos foram modelos de gestão de pessoas e treinamento e desenvolvimento, seguidas de duas outras temáticas com menos da metade das anteriores (tecnologias e sistemas e resultados da gestão de pessoas). As duas temáticas menos frequentes foram recrutamento e seleção e gestão de relações de trabalho. Emergiram outras temáticas, mais frequentes que estas duas e menos frequentes que aquelas quatro (Meneses et al., 2014). Dentre essas seis temáticas, destacam-se duas que são típicas de psicologia do trabalho e das organizações: treinamento e desenvolvimento e recrutamento e seleção, respectivamente com maior e menor frequência. Esses dados confirmam aqueles encontrados por Andrade e Frossard (2013) e por Borges-Andrade e Pagotto (2010).

Quanto à natureza da investigação, um pouco menos da metade efetuou testes estatísticos de relações (Meneses et al., 2014). Prevalece ligeiramente a abordagem qualitativa, seguida da quantitativa e, muito distante, as mistas. Estes autores chamam atenção para o fato de predominarem estudos de natureza descritiva na área de gestão de pessoas, o que limitaria a capacidade da produção científica que deveria fundamentar a prescrição de modelos, procedimentos e técnicas de gestão de pessoas. Isso foi igualmente destacado na revisão de Borges-Andrade e Pagotto (2010), especialmente no que concerne a recrutamento e seleção e avaliação de desempenho. A distribuição equitativa dos setores de inserção (público versus privado) desta revisão foi também confirmada por Meneses et al (2014). Estes finalizam, apontando as contradições entre as estratégias mercadológicas de divulgação de determinados modelos e mecanismos de gestão e a pouca fundamentação do que pretendem vender às organizações.

$\mathrm{Na}$ primeira década do século XXI, presenciou-se, no Brasil, um crescimento expressivo do número de revisões de literatura a 
respeito de tópicos específicos. Isto sugere duas alternativas: 1) sinaliza a autonomia de alguns subdomínios da PO\&T ou, alternativamente, e 2) sugere a intenção de diagnosticar deficiências de pesquisa em certas temáticas, visando articular uma estratégia de superação das mesmas no médio ou longo prazos.

$\mathrm{Na}$ alternativa 1, estão as revisões publicadas por Zerbini e Abbad (2010) e por Bastos, Maia, Rodrigues, Macambira e Borges-Andrade (2014). As primeiras autoras analisaram criticamente a literatura sobre transferência e impacto de treinamento no trabalho. Diagnosticaram a necessidade de investigar preditores relacionados às características dos treinamentos e dos seus participantes, à aquisição de competências e às condições para sua expressão nos ambientes de trabalho. Com isto, poderiam ser desenvolvidos modelos explicativos para aquela transferência e impacto, que melhor fundamentassem a prática profissional. Os segundos autores analisaram 63 artigos nacionais sobre vínculos do empregado com a organização (comprometimento organizacional, contratos psicológicos, cidadania organizacional e percepções de apoio e de justiça e equidade), divulgada na primeira década do presente século. Levaram em conta aspectos metodológicos, de conteúdo, redes de parcerias entre autores e instituições e contribuições e limitações do que foi produzido e publicado. Encontraram situações muito díspares, relativas ao amadurecimento da pesquisa sobre esses vínculos. 0 comprometimento organizacional teria sido o mais intensamente estudado e o de cidadania organizacional o mais carente de estudos. Em termos gerais, entretanto, o diagnóstico desses autores é de que existem sobreposições conceituais e de instrumentos de medida e que a interação entre grupos de pesquisa é pequena.

$\mathrm{Na}$ alternativa 2, estão as revisões publicadas por Brant e BorgesAndrade (2014), Cantal, Borges-Andrade e Porto (2015) e Fonseca, Porto e Borges-Andrade (2015). Os dois primeiros autores analisaram as pesquisas nacionais sobre crenças no contexto do trabalho e as compararam à produção internacional. Encontraram o predomínio da abordagem quantitativa e do desenho de corte transversal, realizados no nível do indivíduo e não em níveis de equipe ou de organizações. Avaliaram que é uma produção numericamente modesta e prevalentemente fundamentada em um único referencial teóricometodológico. A análise da pesquisa brasileira sobre liderança foi o objetivo de Fonseca et al. (2015), que a compararam com a internacional em liderança e com a produção nacional em comportamento organizacional. A pesquisa sobre liderança é majoritariamente exploratória, realizada no setor privado e utiliza entrevistas para coletar dados e análise de conteúdo para tratá-los. Com base naquelas duas comparações feitas, Fonseca et al. (2015) consideraram esta pesquisa ainda em um estágio embrionário. A investigação sobre cidadania organizacional foi o objeto de análise de 
Cantal et al. (2015), que utilizaram a mesma amostra de periódicos de Fonseca et al. (2015) e encontraram um número muito baixo de artigos, tal como Brant e Borges-Andrade (2014), que utilizaram uma amostra de periódicos mais ampla e distinta das duas revisões anteriores. A não delimitação do constructo cidadania organizacional parece ser um problema no Brasil e fora do País. Além deste problema comum, a pesquisa nacional não investigou os consequentes da cidadania organizacional, o que pode prejudicar o julgamento de sua relevância, no campo aplicado. Com base nesses diagnósticos, os autores das três revisões da alternativa 2 recomendaram a construção de agendas de pesquisas para o avanço do conhecimento sobre cidadania organizacional, crenças no trabalho e liderança.

Foram criados periódicos específicos para a subárea, como a rPOT, vinculada à Associação Brasileira de Psicologia Organizacional e do Trabalho (SBPOT), e os Cadernos de Psicologia Social do Trabalho, da Universidade de São Paulo. O primeiro já conseguiu alcançar um dos dois níveis mais elevados de qualidade atribuídos pela Capes ( $A 2$, Qualis Periódicos). Essa criação concentrou parte da produção em periódicos especializados, evitando a dispersão, que dificulta uma visão clara de tendências. É fato que psicólogos de PO\&T publicam em periódicos de administração e frequentam congressos de áreas afins. Mas não resta dúvida que o surgimento de periódicos especializados auxilia a traçar um panorama mais claro e a dar uma diretriz para o desenvolvimento desta subárea. Ou seja, definir sua identidade. A publicação, por exemplo, do livro Psicologia, Organizações e Trabalho no Brasil (Zanelli et al., 2004, 2014), contribuiu de modo significativo para orientar o ensino da subárea nos cursos de graduação em psicologia e também da pós-graduação no país. Substituiu os livros traduzidos, baseados em estudos feitos em outras culturas, e textos isolados publicados em periódicos, que não tinham a preocupação formativa. Aspectos conceituais e resultados de pesquisas na subárea, redigidos por estudiosos, permitem sistematizar melhor o aprendizado e a formação dos futuros interessados em PO\&T. Ainda no campo teórico, foi publicado o primeiro dicionário brasileiro desta subárea, que reflete o seu mosaico de distintas perspectivas e visa facilitar o diálogo entre seus profissionais e apoiar a formação dos seus estudantes (Bendassolli \& Borges-Andrade, 2015). O mencionado dicionário tem verbetes relacionados a redes teóricas de articulação e a demandas da prática, do ensino e da investigação, escritos por quase oitenta pessoas.

Ocorreram cinco publicações relativamente recentes sobre avaliação e medidas para PO\&T, o livro organizado por Primi e Baumgartl (2006), o de Abbad et al. (2012), os dois organizados por Siqueira (2008, 2014) e o organizado por Puente-Palácios e Peixoto (2015). Tornaram disponível uma grande e diversificada coletânea de 
instrumentos de medida com evidências de validade no país. Até então, embora tais instrumentos de medida existissem, ficavam dispersos em artigos científicos diversos e frequentemente só disponíveis nas bibliotecas universitárias depositárias das dissertações de mestrado e teses de doutorado. Em 2016, a rPOT publicou um número temático com ensaios sobre a fragmentação teórica em PO\&T e sua origem, consolidação e perspectivas, seus modelos explicativos e articulação de níveis, a regulação e controle ético da sua investigação e as questões do dizer e fazer, dos desenhos longitudinais e dos paradigmas em suas pesquisas.

\section{Considerações finais}

Seis pontos resumem os principais aspectos a serem considerados sobre o desenvolvimento da subárea de PO\&T no Brasil. O primeiro se refere ao papel da pós-graduação no crescimento e na consolidação desta subárea. Em comparação com o início dos anos 2000, verificase um aumento expressivo da sua presença nos Programas de Pósgraduação em Psicologia. Seria maior, se a ele fosse incorporada a presença da PO\&T em linhas de pesquisa da área de administração, por exemplo. Esta subárea hoje se apresenta, com a sua diversidade característica, nesses Programas, em quase todas as regiões do país. Ocorreu aumento do número de projetos e de linhas de pesquisa nos mesmos.

O segundo ponto diz respeito à produção científica. Durante muitos anos, a formação em PO\&T esteve apoiada em artigos e materiais textuais da área de administração e outras áreas afins. Em 2004, a publicação de um livro reorientou completamente essa tendência. Considerado um êxito editorial, teve uma segunda edição (2014) completamente revista, atualizada e mais direcionada ao ensino. Abriu caminho para uma série de publicações sob a forma de livros e manuais no Brasil, fruto de produções de grupos de trabalho da Associação Nacional de Pesquisa e Pós-graduação em Psicologia (ANPEPP). Mudou o cenário da formação. A criação de associações científicas e de revistas especializadas nos anos 2000 igualmente contribuiu para o escoamento de uma produção na área, embora grande parte dessa produção siga sendo divulgada em periódicos da área de administração.

O terceiro ponto se refere a questões temáticas da área. As diversas revisões de literatura aqui apresentadas e a análise dos títulos dos projetos sugerem que as fronteiras demarcatórias dos subcampos de PO\&T - trabalho, organizações e gestão - apresentam-se mais flexíveis. Mas enfrentam tensões. Pesquisadores que se dedicam ao estudo de condições de trabalho e precarização se situam distantes daqueles que se debruçam ao estudo de processos organizacionais no 
nível micro e meso. O cenário mais amplo, incluindo as revisões de literatura apresentadas, sinaliza três fortes nichos, pautados em: (i) crítica das condições de trabalho contemporâneas, articulando análises teóricas e propostas de intervenção (e.g., clínicas do trabalho, ergonomia da atividade, abordagens psicossociais, qualidade de vida no trabalho, gestão humanizada de pessoas), (ii) produção conceitual sobre comportamento humano nas organizações em que o trabalho é um elemento estruturante (e.g., vínculos com o trabalho, processos grupais, liderança, cultura, cidadania organizacional, carreiras, equipes), (iii) produção de ferramentas de avaliação, de diagnóstico e de intervenção no âmbito da gestão (e.g., avaliação de treinamento, desempenho).

O quarto ponto está relacionado a aspectos metodológicos. As revisões mencionadas neste artigo sugerem haver relações entre temas de interesses dos estudiosos e desenhos metodológicos. Além disso, essa produção parece ter relação com o método utilizado nos estudos. Temas mais alinhados ao comportamento organizacional, a que se dedicam mais psicólogos, apoiam-se em desenhos correlacionais de pesquisa e na construção de instrumentos. A produção na área da gestão, divulgada em periódicos de administração, possui um caráter mais descritivo e faz mais uso de desenhos qualitativos, mesmo em temas considerados estratégicos como liderança. Na psicologia, ao contrário, encontra-se uma produção mais consolidada em gestão, particularmente no que tange ao treinamento, desenvolvimento e à educação, explicada pela atuação de grupos de pesquisa específicos e políticas governamentais que generosamente os financiaram. Mas quase nada é pesquisado sobre recrutamento e seleção. Outra agravante é que há poucos indícios de estudos longitudinais atinentes a processos dinâmicos que circunscrevam o mundo do trabalho e das organizações. Há também poucas novidades metodológicas no desenho de pesquisas, o que de fato coloca limites ao desenvolvimento de algumas áreas temáticas em PO\&T.

O quinto se refere ao crescimento dos estudos de revisão de literatura na área. Revela preocupação no sentido de compreender o cenário atual, identificar lacunas teórico-metodológicas e analisar criticamente o estado de arte. Seu objetivo é o de sugerir diretrizes para o desenvolvimento da produção científica e atuação profissional na subárea. Críticas internas facilitam o alinhamento teóricometodológico e o diálogo crítico. Essas revisões podem ter o efeito de delimitar campos do conhecimento específicos e fortalecer identidade dos pesquisadores e de seus grupos. Contudo, ainda não permitem traçar um perfil abrangente das decisões metodológicas da vasta e diversificada subárea de PO\&T. Ora as revisões se concentram em alguns periódicos, ora se detêm em temáticas muito específicas. Podem conduzir a possíveis vieses quando se trata de analisar o perfil 
dominante de investigação científica e as práticas emergentes. Está por ser realizado ou divulgado um estudo mais abrangente, abarcando os principais tópicos e o conjunto dos periódicos nacionais da psicologia, administração, ciências da saúde, educação, ciências sociais e áreas afins. Além disto, com a pressão atual para internacionalização, feita pelas agências de apoio à pesquisa e pósgraduação, uma parte significativa da produção intelectual pode ter passado a ser veiculada em periódicos publicados fora do Brasil. Eles não poderiam ser excluídos desse estudo mais abrangente. Relatos de pesquisa ainda são publicados em coletâneas, dificilmente disponíveis para pessoas distantes dos grupos que as organizaram. Há as dissertações e teses nas bibliotecas ou repositórios de universidades, nunca transformadas em artigos, livros ou capítulos de livros.

Para finalizar, a produção científica de qualquer campo do saber está diretamente implicada no modo de se fazer ciência. Se as questões epistemológicas tentam responder qual conhecimento pode ser considerado válido, as questões metodológicas tentam dar uma resposta sobre o modo como se constrói conhecimento válido. Existem dois níveis de indagações metodológicas: 1) como construir boas teorias que possam obedecer a critérios de consistência interna e coerência empírica e 2) como produzir conhecimento empírico válido que contribua para a generalização teórica e empírica. Eles colocam desafios respectivamente para 1) a sustentação de proposições derivadas de teorias e 2) a generalização dos resultados para outros contextos e situações similares. A produção de boas teorias e o teste empírico de hipóteses delas derivadas caminham juntas. No campo das ciências factuais, como é o caso da PO\&T, a sofisticação de ferramentas metodológicas sem uma boa teoria não produz grandes avanços. Uma teoria, todavia, não consegue avançar na ausência de bons métodos que testem empiricamente sua validade (Van Maanen, Sorensen, \& Mitchell, 2007). Existem sinais de que há uma trilha aberta para o desenvolvimento teórico e metodológico brasileiro em PO\&T. Seu fortalecimento depende de diálogo com a própria psicologia e áreas afins.

\section{Referências}

Abbad, G. S., Mourão, L., Meneses, P. P. M., Zerbini, T., BorgesAndrade, J. E., \& Vilas-Boas, R. (Orgs.). (2012). Medidas de avaliação em treinamento, desenvolvimento e educação: Ferramentas para gestão de pessoas. Porto Alegre: Artmed.

Andrade, A. L., \& Frossard, V. L. (2013). Produção científica sobre fatores humanos no trabalho: Análise a partir de periódicos brasileiros. Revista Psicologia: Organizações e Trabalho, 13(1), 
89-98.

Recuperado

de

http://pepsic. bvsalud.org/scielo.php?script=sci_arttext\&pid=S1

984-66572013000100008\&lng =pt\&nrm =iso\&tlng $=$ pt

Bastos, A. V. B., \& Gondim, S. M. G. (Orgs.). (2010). O trabalho do psicólogo no Brasil. Porto Alegre, RS: Artmed.

Bastos, A. V. B., Maia, L. G., Rodrigues, A. C. A., Macambira, M. O., \& Borges-Andrade, J. E. (2014). Vínculos dos indivíduos com a organização: Análise da produção científica brasileira 20002010. Psicologia: Teoria e Pesquisa, 30(2), 153-162. doi: 10.1590/s0102-37722014000200004

Bendassolli, P. F., \& Borges-Andrade, J. E. (Orgs.). (2015). Dicionário de psicologia do trabalho e das organizações. São Paulo: Casa do Psicólogo/Pearson.

Borges, L. de O., \& Mourão, L. (Orgs.). (2013). O trabalho e as organizações: Atuações a partir da psicología. Porto Alegre: Artmed.

Borges-Andrade, J. E., \& Pagotto, C. P. (2010). O estado da arte da pesquisa brasileira em psicologia do trabalho e organizacional. Psicologia: Teoria e Pesquisa, 26(número especial), 37-50. doi: 10.1590/S0102-37722010000500004

Borges-Andrade, J. E., \& Zanelli, J. C. (2014). Psicologia e produção do conhecimento em organizações e trabalho. In J. C. Zanelli, J. E. Borges-Andrade, \& A. V. B. Bastos (Orgs.), Psicologia, organizações e trabalho no Brasil (pp. 583-608). Porto Alegre, RS: Artmed.

Brant, S. R. C., \& Borges-Andrade, J. E. (2014). Crenças no contexto do trabalho: Características da pesquisa nacional e estrangeira. Revista Psicologia: Organizações e Trabalho, 14(3), 292-302. Recuperado de http://pepsic. bvsalud.org/scielo.php?script=sci_arttext\&pid=S1 984-66572014000300005

Camargo, B. V. (2005). ALCEST: Um programa informático de análise quantitativa de dados textuais. In A. S. P. Moreira (Org.) Perspectivas teórico-metodológicas em representações sociais (pp.511-539). João Pessoa: Ed. Universitária UFPB.

Cantal, C., Borges-Andrade, J. E., \& Porto, J. B. (2015). Cooperação, comportamentos proativos ou simplesmente cidadania organizacional? Uma revisão da produção nacional na área. Revista Psicologia: Organizações e Trabalho, 15(3), 286-297. doi: 10.17652/rpot/2015.3.331

Coordenação de Aperfeiçoamento de Pessoal de Nível Superior (Capes). (2017). Infocapes: Psicologia. Documento de área da Psicologia. Recuperado http://www.capes.gov.br/component/content/article/44avaliacao/4681-psicologia 
Fonseca, A. M. O., Porto, J. B., \& Borges-Andrade, J. E. (2015). Liderança: Um retrato da produção científica brasileira. Revista de Administração Contemporânea, 19(3), 290-310. doi: 10.1590/1982-7849rac20151404

Meneses, P. P. M., Coelho Jr, F. A., Ferreira, R. R., Paschoal, T., \& Silva Filho, A. I. (2014). A produção científica brasileira sobre a gestão de recursos humanos entre 2001 e 2010. Revista de Administração Mackenzie. 15(4), 110-134. Recuperado de http: //www. redalyc. org/articulo. oa? id=195432529005

Primi, R., \& Baumgartl, V. O. (2006). Contribuições da avaliação psicológica no contexto organizacional. São Paulo, SP: Casa do Psicólogo.

Puente-Palácios, K., \& Peixoto, A. L. A. (Org.). (2015). Ferramentas de diagnóstico para organizações e trabalho: Um olhar a partir da psicologia. Porto Alegre, RS: Artmed.

Siqueira, M. M. M. (Org.). (2008). Medidas do comportamento organizacional: Ferramentas de diagnóstico e de gestão. Porto Alegre, RS: Artmed.

Siqueira, M. M. M. (Org.). (2014). Novas medidas do comportamento organizacional: Ferramentas de diagnóstico e de gestão. Porto Alegre, RS: Artmed.

Tonetto, A. M., Amazarray, M. R., Koller, S. H., \& Gomes, W. B. (2008). Psicologia organizacional e do trabalho no Brasil: Desenvolvimento científico contemporâneo. Psicologia e Sociedade, 20(2), 155-164. doi:10.1590/S010271822008000200003

Van Maanen, J., Sorensen, J. B., \& Mitchell, T. R. (2007). Introduction to special topic fórum: The interplay between theory and method. Academy of Management Review, 32, 1145-1154. doi: 10.2307/20159360

Vergara, S. C., \& Peci, A. (2003). Escolhas metodológicas em estudos organizacionais. Organizações \& Sociedade, 10(27), 13-26. doi: 10.1590/S1984-92302003000300001

Zanelli, J. C., Bastos, A. V. B., \& Borges-Andrade, J. E. (Orgs.). (2004). Psicologia, organizações e trabalho no Brasil. Porto Alegre, RS: Artmed.

Zanelli, J. C., Bastos, A. V. B., \& Borges-Andrade, J. E. (Orgs.). (2014). Psicologia, organizações e trabalho no Brasil. Porto Alegre, RS: Artmed.

Zerbini, T., \& Abbad, G. S. (2010). Transferência de treinamento e impacto do treinamento no trabalho: Análise crítica da literatura. Revista Psicologia: Organizações e Trabalho, 10(2), 97-111.

Recuperado

https://periodicos.ufsc. br/index.php/rpot/article/view/22212 


\section{Endereço para correspondência \\ Sonia Maria Guedes Gondim}

Universidade Federal da Bahia - UFBA

Instituto de Psicologia - Programa de Pós-Graduação em Psicologia

Rua Aristides Novis, 197, Federação, CEP 40210-630, Salvador - BA, Brasil

Endereço eletrônico: sggondim@gmail.com

\section{J airo Eduardo Borges-Andrade}

Universidade de Brasília - UnB

Instituto de Psicologia

Programa de Pós-graduação em Psicologia Social, do Trabalho e das Organizações

ICC Sul, Campus Darcy Ribeiro, Asa Norte, CEP 70910-900, Brasília - DF, Brasil

Endereço eletrônico: jairo.borges@gmail.com

\section{Antônio Virgílio Bittencourt Bastos}

Universidade Federal da Bahia - UFBA

Programa de Pós-Graduação em Psicologia

Superintendência de Avaliação e Desenvolvimento Institucional - SUPAD

Campus Universitário de Ondina, s/n, Pavilhão 4, Ondina, CEP 40170-155, Salvador

- BA, Brasil

Endereço eletrônico: antoniovirgiliobastos@gmail.com

Recebido em: 04/11/2018

Aceito em: 06/01/2019

\section{Notas}

* Psicóloga, Mestre e Doutora pela Universidade Federal do Rio de Janeiro. Realizou estudos pós-doutorais na Universidade Complutense de Madrid. Professora da graduação, mestrado e doutorado no Instituto de Psicologia da Universidade Federal da Bahia. Atua no Centro Interdisciplinar de Desenvolvimento e Gestão Social da UFBA. Principais interesses de pesquisa são emoções e trabalho, regulação emocional, mapeamento de competências, competências profissionais, identidade profissional, métodos qualitativos, especialmente grupos focais, formação e desenvolvimento de gestores. Bolsista 1D do CNPq.

** Psicólogo, Mestre e Doutor em Sistemas Instrucionais pela Florida State University. Estágios de pós-doutorado realizados: International Food Policy Research Institute, University of Sheffield e Rijksuniversiteit Gröningen e Instituto Superior de Ciências do Trabalho e da Empresa. Atua na graduação e pósgraduação do Instituto de Psicologia da UnB. Professor titular da Universidade de Brasília. Seus principais temas de pesquisa são: aprendizagem, processos psicossociais, mudança organizacional. Atua também com treinamento $\mathrm{e}$ desenvolvimento de pessoas. Bolsista $1 \mathrm{~A}$ do CNPq.

*** Psicólogo, Mestre e Doutor pela Psicologia pela Universidade de Brasília (1994), com concentração em Psicologia Organizacional e do Trabalho. Professor titular de Psicologia Social das Organizações, no Instituto de Psicologia da Universidade Federal da Bahia. Foi membro do Conselho Federal de Psicologia (1984-1988) e presidente em1986. Atuou como membro da comissão de especialistas em ensino de Psicologia do MEC/SESu (1994-2000). Foi membro do CA de Psicologia do CNPq, da Comissão de Psicologia do INEP e da comissão de área da Psicologia na CAPES. Atualmente é Coordenador da Área de Psicologia da CAPES e membro, no INEP, da Comissão de Psicologia para o ENADE. Pesquisador I-A do CNPq, atuando principalmente em temas da área de Comportamento Organizacional, a exemplo de: comprometimento no trabalho, mudanças organizacionais.

Este artigo de revista Estudos e Pesquisas em Psicologia é licenciado sob uma Licença Creative Commons Atribuição-Não Comercial 3.0 Não Adaptada. 